\title{
RESSIGNIFICAR E COEXISTIR: TÁTICAS NO ESPAÇO RESIDUAL
}

Victor Martins de Aguiar

Arquiteto e Urbanista, Mestre pela Universidade de São Paulo. E-mail: victormarq90@gmail.com

\section{RESUMO}

No contexto das metrópoles contemporâneas às vezes nos deparamos com espaços residuais, como os baixios de viadutos. Este trabalho pretende proporcionar uma reflexão sobre ações, que almejam ao transgredir práticas, oferecer respostas para espaços tratados como resíduo, abandonado e sem valor. Nessa leitura, entende-se a cidade como um processo de construção diário e as intervenções propostas como um romper para a geração de novas possibilidades programáticas. Essa reflexão também aponta para uma nova compreensão do que é arquitetura, urbanismo e cidade, o que vem exigindo o repensar de situações no espaço urbano para a ocupação dos espaços públicos.

Palavras-chave: espaço residual; espaço público; encontro; permanência.

\section{RESSIGNIFY AND COEXIST: TACTICS IN RESIDUAL SPACE}

\begin{abstract}
In the context of contemporary metropolises we sometimes encounter residual spaces, such as the underpasses of viaducts. This work intends to provide a reflection on actions that aim to transgress practices, offer answers to spaces treated as waste, abandoned and worthless. In this reading, the city is understood as a process of daily construction and the interventions proposed as a break for the generation of new programmatic possibilities. This reflection also points to a new understanding of what is architecture, urbanism and city, which has required the rethinking of situations in the urban space for the occupation of public spaces.
\end{abstract}

Keywords: residual space; public space; permanence; meeting.

\section{INTRODUÇÃO}

Nas cidades brasileiras as intervenções públicas buscaram resolver mais a demanda do transporte privado do que o público. O que resultou em intervenções desestruturantes - prática do que seria chamado de urbanismo rodoviarista. Com reflexos até os dias de hoje, passarelas, pontes e viadutos são projetadas para responder um único problema: ligar áreas na cidade. Essa forma de intervir garantiu continuidade no fluxo de automóveis (AGUIAR, 2013). No entanto, as "sobras" dessas intervenções se estabeleceram em espaços abandonados e passaram a ser territórios de uma resistência solitária - a da cidadania não plena.

Tal consequência é visível nos baixios de viadutos, onde o temor de que são lugares feios e inseguros não contribui para a aproximação das pessoas e aquelas que geralmente passam por eles observa-se um caminhar ligeiro. Talvez por essas questões, é que uma parcela da população se sente segura nos baixios como os moradores de rua.

Os moradores de rua nos baixios de viadutos projetam suas atividades cotidianas. No desenvolvimento dessas atividades (abrigo, trabalho, lazer e outras) atrela-se um modo de vida liberto de convenções sociais que reinventa maneiras de sobreviver na cidade. Já, Teixeira, Cajado e Agostini (2008) destacam que os baixios deveriam ser de uso público e destinados para projetos sociais. Não parece ruim também prever nos baixios de viadutos usos para quem ali transita.

Nessa visão, criaram-se novas possibilidades de uso dos viadutos. Essas possibilidades deveriam assumir o caráter da improvisação, do inusitado, da fluidez para moldar-se às exigências 
de um espaço dinâmico (GUATELLI, 2012). Desse modo, o viaduto passaria a ser um receptáculo aberto ao que chega e ao que está porvir - a fim de dar suporte para ações, semelhante ao projeto Parasite de Las Palmas de 2001, do escritório Korteknie Stuhlmacher Architecten, em Rotterdam (Figura 1). No projeto, um protótipo pré-fabricado foi instalado na parte superior do poço do elevador de um armazém abandonado ${ }^{1}$. A estrutura pré-fabricada, como um parasita, utilizou-se das redes de água, esgoto e eletricidade do armazém e recebeu exposições temporárias.

Figura 1: O protótipo do projeto Parasite de Las Palmas de 2001 se apoiou como um "parasita" em um espaço residual, no ano em que Rotterdam foi a Capital Europeia da Cultura.
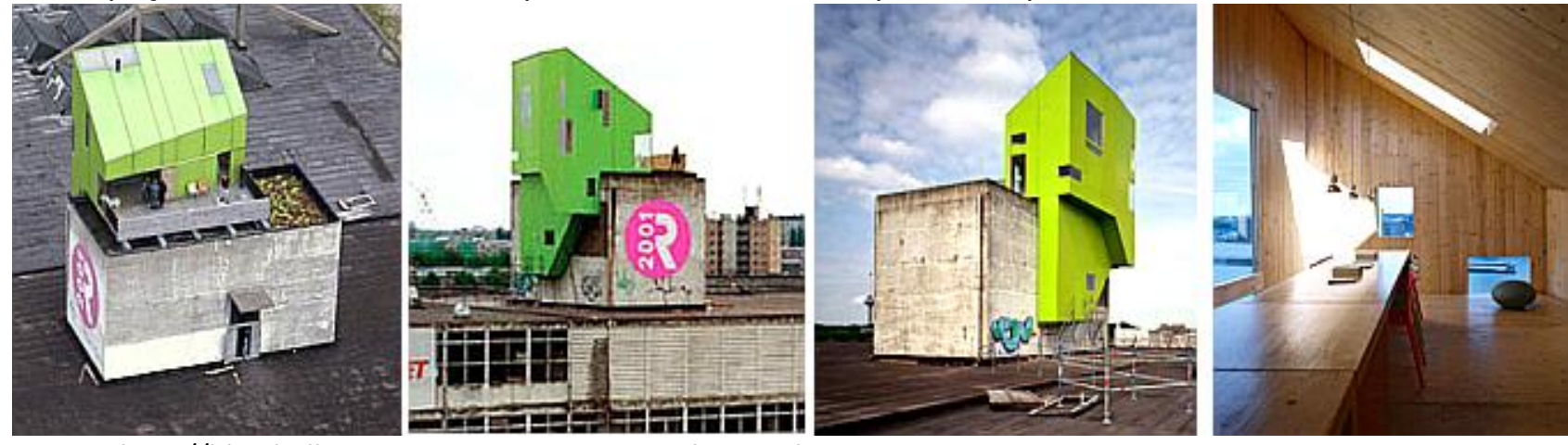

Fonte: <http://blog.bellostes.com>. Acesso em: 02 de ago. de 2017.

Com maior frequência, hoje se presencia na cidade situações que rompem, mesmo que momentaneamente, com o original pensado para o local. Esse romper se dá através de usos não previstos como apropriados, mas que proporcionam a abertura para diferentes ocupações das estruturas viárias, por exemplo (SOUZA; ABASCAL, 2014).

Na proposição de outros usos em São Paulo para as estruturas viárias nota-se o viaduto Doutor Arnaldo que, desde os anos 1990, é ocupado por grupos para a prática de rapel e tirolesa. Em intervenções mais recentes na cidade como "A Cidade É Para Brincar. Sou Criança de 0 a 99 Anos" do coletivo Basurama para a Virada Cultural de 2013, buscou-se questionar o espaço urbano como local de brincadeira a partir da instalação de balanços de pneus no viaduto do Chá ${ }^{2}$ (Figura 2). Os balanços de pneus do Basurama em 2013 também foram instalados no Minhocão, durante o Festival BaixoCentro ${ }^{3}$. Essas intervenções temporárias indicam que a cidade e, logo, seus espaços públicos podem receber outros usos, desde que adotada a premissa da efemeridade e da experimentação.

\footnotetext{
${ }^{1}$ A instalação do protótipo levou apenas alguns dias, apesar do antigo armazém ser bastante inacessível. Disponível em: <http://www.kortekniestuhlmacher.nl/?q=node/9>. Acesso em: 02 de ago. de 2017.

${ }^{2}$ A intervenção para a Virada Cultural de 2013 foi mais uma proposta implantada pelo Basurama nos espaços públicos de São Paulo, um trabalho realizado desde 2007. Disponível em: http://basurama.org/pt-br/projetos/a-cidade-e-parabrincar-virada-cultural-2013-2/>. Acesso em: 02 de ago. de 2017.

${ }^{3}$ A instalação fez parte da intervenção Parque de Diversões Minhocão e contou com a parceria de mais dois coletivos para a sua realização, o MUDA e o Sociedade Anônima. Disponível em: <http://basurama.org/pt-br/projetos/parquede-diversoes-minhocao-2>. Acesso em: 02 de ago. de 2017.

Colloquium Socialis, Presidente Prudente, v. 01, n. Especial 2, Jul/Dez, 2017, p.758-765. DOI: 10.5747/cs.2017.v01.nesp2.s0225
} 
Figura 2: O valor desses usos temporários para a cidade, como os balanços instalados no viaduto do Chá em 2013 pelo Basurama, está em indicar diferentes formas de ocupação dos espaços públicos.
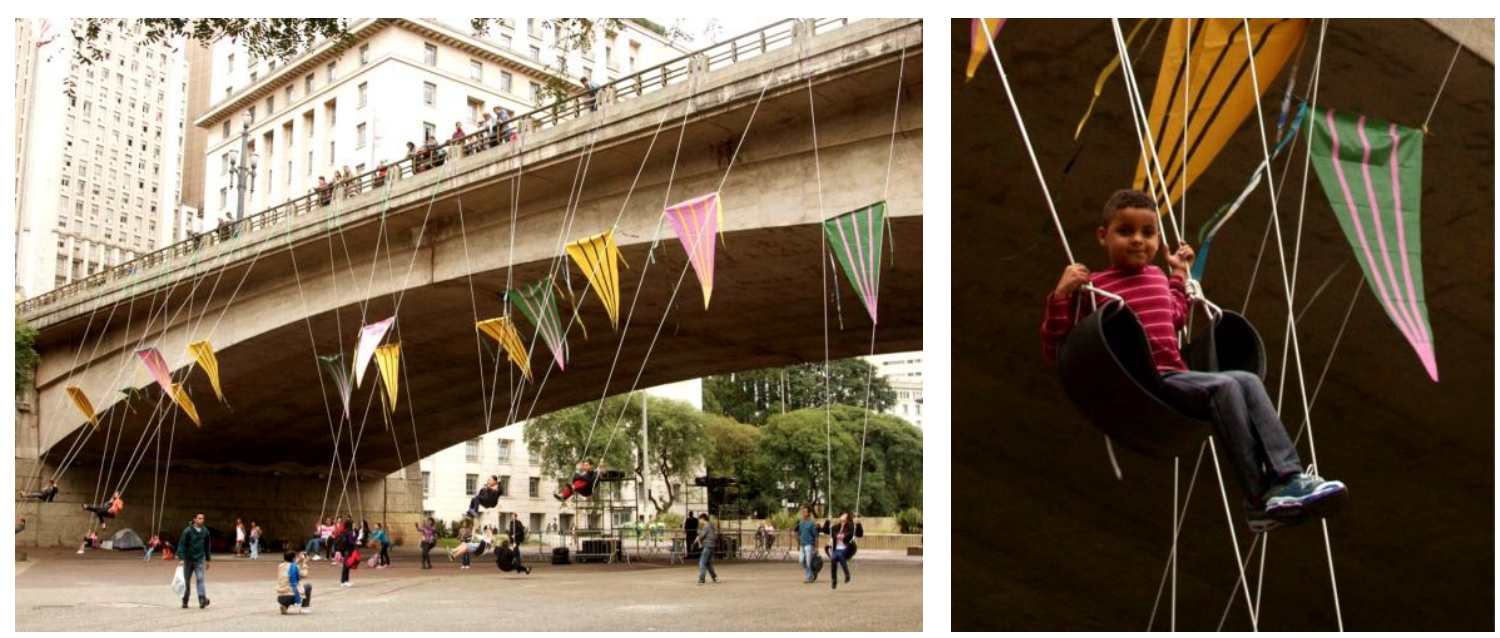

Fonte: <http://www.archdaily.com.br/br/01-118456/a-cidade-e-para-brincar-slash-basurama>. Acesso em: 02 de ago. de 2017.

O Festival BaixoCentro ocorreu em três edições, 2012, 2013 e 2014, na região do Minhocão, a fim de incentivar a retomada de espaços abandonados e maior interação entre as pessoas ${ }^{4}$. Em todas as edições foi adotado pelos organizadores o conceito de "cuidadoria", isto é, os produtores e colaboradores deveriam ajudar na realização das atividades culturais (MOVIMENTO BAIXOCENTRO, 2013). A partir dessa premissa buscou-se estimular: a ocupação do espaço público, a reflexão de para quem é à cidade e a participação dos moradores na produção do evento.

Os espaços abandonados para Rocha (2008) são aqueles que fogem às regras e que estão fora da normalidade, pois não existe norma para o caos. Na visão do autor, nesses espaços somos livres para entrar em outra dimensão arquitetônica: de "onde tudo é possível". O que torna aceitável, então a transformação de estruturas viárias em local de encontro e de permanência.

Desse modo, parece fundamental revelar o potencial dos espaços residuais e destacar que nem todas as ocupações das estruturas são negativas. Ao contrário, às vezes elas são capazes de estimular a liberdade individual ou de grupos e originar espaços públicos.

\section{METODOLOGIA}

O desenvolvimento deste trabalho se deu através de consultas em fontes de dados secundárias, como livros, artigos e sites da Internet, com o intuito de compor o embasamento teórico sobre: espaço residual, espaço público e apropriação informal. Também houve a pesquisa de projetos de arquitetura voltados para a ocupação de baixios de viadutos a partir do trabalho coletivo.

\section{DISCUSSÃO}

Ao se valer da permanência para a ocupação da cidade Moehlecke (2005) destaca-a como possibilidade de aumentar a potência do corpo - abri-lo para outras situações. Em estado de permanência para a autora o corpo não apenas significa oposição à velocidade, mas, sim, requisição para outras composições. Composições que primam novas descobertas e práticas do

\footnotetext{
${ }^{4}$ Nas três edições, o festival foi realizado de maneira horizontal, associativa e independente com o objetivo de destacar o potencial do trabalho coletivo. Disponível em: <http://baixocentro.org/>. Acesso em: 02 de ago. de 2017.
} 
ser que transita e vive à cidade. Para tal operação, é fundamental empregar os espaços residuais e os vazios porque não condizem com a lógica da cidade - da totalidade da ocupação.

Não sem razão, tem-se percebido a importância dos vazios no processo de acolhimento da subjetividade nos projetos de arquitetura. Contudo não bastam os vazios desprogramados, é preciso haver neles latência para que usos sejam acionados e estimulados. Uma latência obtida através da combinação de tensões programáticas (GUATELLI, 2008).

A combinação de tensões programáticas se desdobra na teoria da disjunção arquitetônica $^{5}$ de 1988 do arquiteto Bernard Tschumi. Como exemplos de disjunção, Tschumi imagina a possibilidade de praticar salto com vara em uma igreja, andar de bicicleta em uma lavanderia e praticar skydiving no shaft de um elevador. $O$ arquiteto supõe, por exemplo, no projeto Bridge City de 1988, para Lausanne, que as quatro pontes a serem implantadas ali implicariam em um constante movimento de usuários ${ }^{6}$ (Figura 3). Tal movimento seria possível por elas abrigarem programas distintos, os quais ocasionariam "choques" e estimulariam eventos inesperados.

Figura 3: Cada ponte do projeto Bridge City de 1988 acomodaria dois usos: na parte superior um uso público ou comercial e no nível inferior a circulação de pedestres.

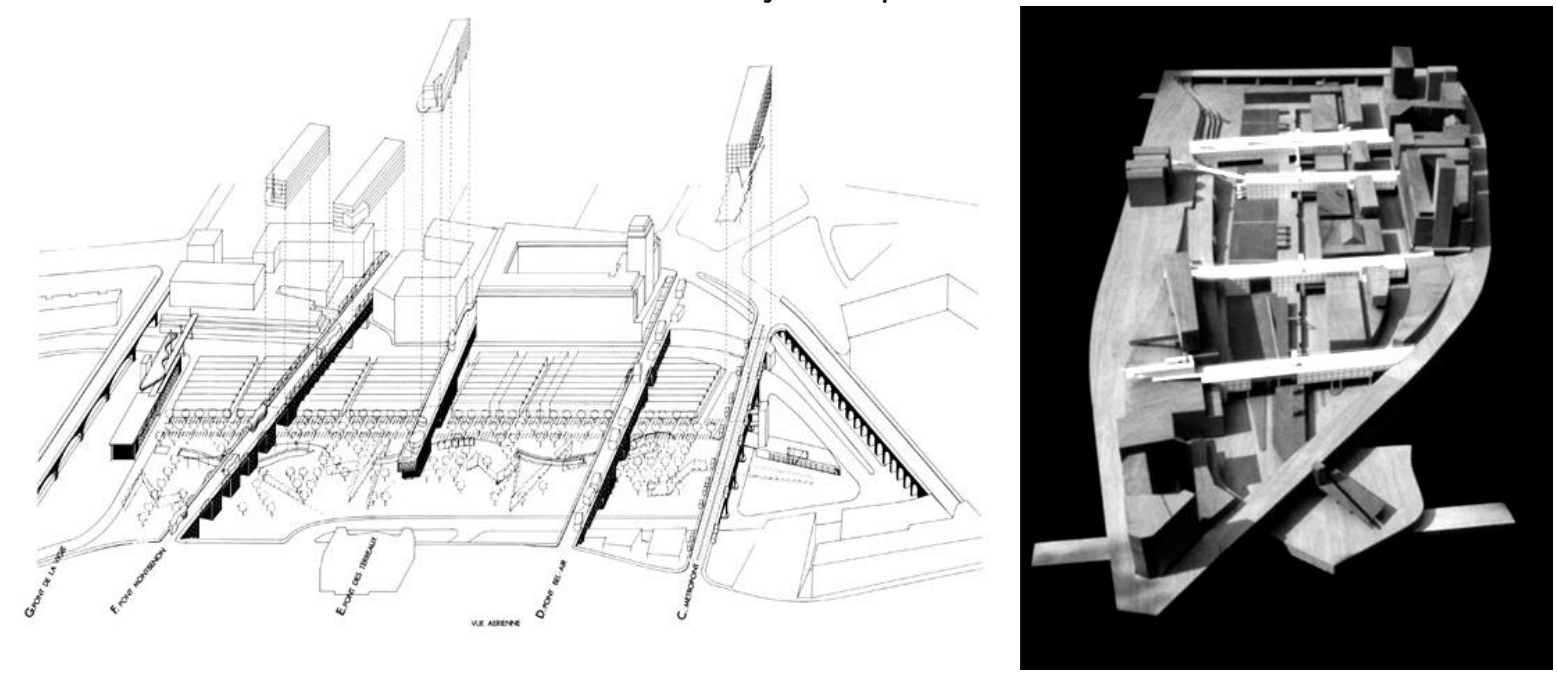

Fonte: <http://www.tschumi.com/projects/31/>. Acesso em: 03 de ago. de 2017.

Não cabe portanto apenas "deixar o projeto correr", compete ao arquiteto e urbanista dar forma aos espaços e dotá-los de flexibilidade para inseri-los na dinâmica do tempo. Assim, uma questão importante de colocar: Quais as escolhas a serem priorizadas no projeto para alcançar tal objetivo?

As escolhas passariam para Jacques (2005) pela experiência corporal com a cidade. Mais do que isso, pela experiência sensorial, podendo até ser erótica. Só a experiência com a cidade, segundo a autora não permite a redução do espaço em uma simples imagem. A cidade ao ser vivenciada deixa de ser uma "cenografia", ela ganha corpo, torna-se um "outro" corpo a partir da ressignificação (MOEHLECKE, 2005).

A ação de ressignificar um espaço abandonado com propostas pautadas na liberdade, imaginação e experimentação tem revelado que o que realmente importa na ação projetual é

\footnotetext{
${ }^{5}$ Maiores informações consultar: TSCHUMI, Bernard. Introdução: notas para uma teoria da disjunção arquitetônica, 1988. In: NESBITT, Kate (Org.). Uma nova agenda para a arquitetura: antologia teórica 1965-1995. São Paulo: Cosac Naify, 2006. p. 188-91.

6 Os usos propostos para cada uma das pontes almejavam atrair um público amplo. Disponível em: <http://www.tschumi.com/projects/31/>. Acesso em: 03 de ago. de 2017.

Colloquium Socialis, Presidente Prudente, v. 01, n. Especial 2, Jul/Dez, 2017, p.758-765. DOI: 10.5747/cs.2017.v01.nesp2.s0225
} 
repensar problemas, reconsiderar situações e descobrir novas maneiras de responder questões, sem tomar partido de soluções evidentes, universais ou eternas.

\section{RESULTADOS}

Recentes projetos de estruturas viárias estão compreendendo-as segundo agentes potencializadores e suportes para futuros eventos, como o projeto Jean Jacques Bosc Bridge de 2013, para Bourdeaux, do escritório OMA. O projeto buscou repensar a função cívica e o simbolismo de uma ponte no século 21 . Ao prever programas públicos, bem como, flexibilidade para acomodar futuras necessidades, o memorial do projeto destaca: "A ponte em si não é o 'evento' na cidade, mas uma plataforma que pode acomodar todos os acontecimentos da cidade" 7 (Figura 4).

Figura 4: A importância do projeto Jean Jacques Bosc Bridge de 2013 não está na ponte em si, mas na sua flexibilidade de uso. A sua faixa de rodagem poderá ser configurada para diferentes tráfegos e eventos.
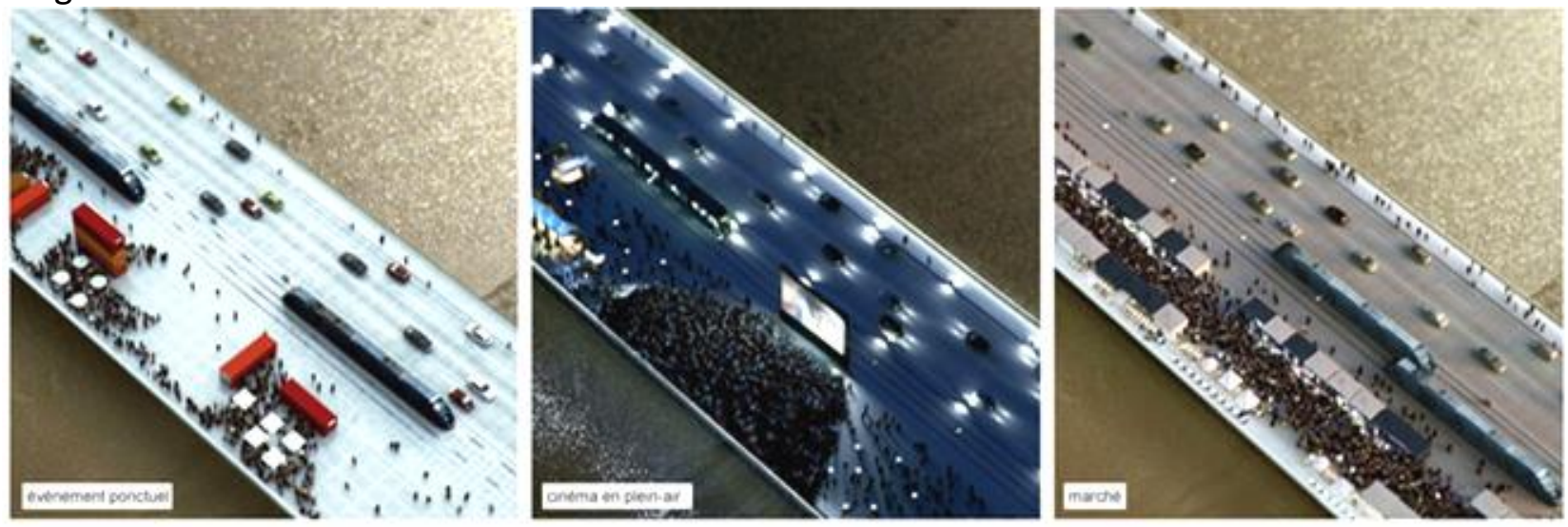

Fonte: <http://oma.eu/projects/jean-jacques-bosc-bridge>. Acesso em: 03 de ago. de 2017.

Infelizmente, o projeto Jean Jacques Bosc Bridge demonstra valor na ocupação da área superior da ponte, enquanto os baixios são pouco legitimados. A respeito dos baixios observa-se que continuam sendo discutidos por projetos experimentais, como o Autobarrios San Cristóbal $^{8}$ de 2012, em Madrid, realizado pelo coletivo Basurama com a participação de moradores locais.

O Basurama definiu no projeto um programa de requalificação para a área inferior de uma ponte. Para transformar a área abandonada em um espaço público útil, o coletivo idealizou a intervenção em quatro etapas: pesquisa; concepção do projeto; capacitação e construção; autogestão e uso diário. Essas etapas tinham o propósito de atender as necessidades dos moradores do bairro, além de estimular a imaginação deles na ocupação do espaço. A primeira ação no baixio, após reuniões com os moradores, foi a implantação do mural "Barrio del Color", em conjunto com o grupo BoaMistura, e, por fim, mobiliários foram construídos com a colaboração do Collectif Etc (Figura 5).

\footnotetext{
${ }^{7}$ Todos os modais de transporte (veículos privados, transporte público, bicicletas) são acomodados na faixa de rodagem, porém há destaque para os usos dos pedestres no projeto. Disponível em: <http://www.archdaily.com.br/br/01-163683/oma-vence-competicao-para-sua-primeira-ponte-pont-jean-jacquesbosc>. Acesso em: 03 de ago. de 2017.

${ }^{8} \mathrm{~A}$ intervenção se pautou na construção coletiva para incentivar a autogestão do baixio da ponte. Disponível em: <http://basurama.org/proyecto/autobarrios-sancristobal/>. Acesso em: 04 de ago. de 2017.

Colloquium Socialis, Presidente Prudente, v. 01, n. Especial 2, Jul/Dez, 2017, p.758-765. DOI: 10.5747/cs.2017.v01.nesp2.s0225
} 
Figura 5: Os mobiliários do projeto Autobarrios San Cristóbal de 2012 foram construídos com materiais descartados.

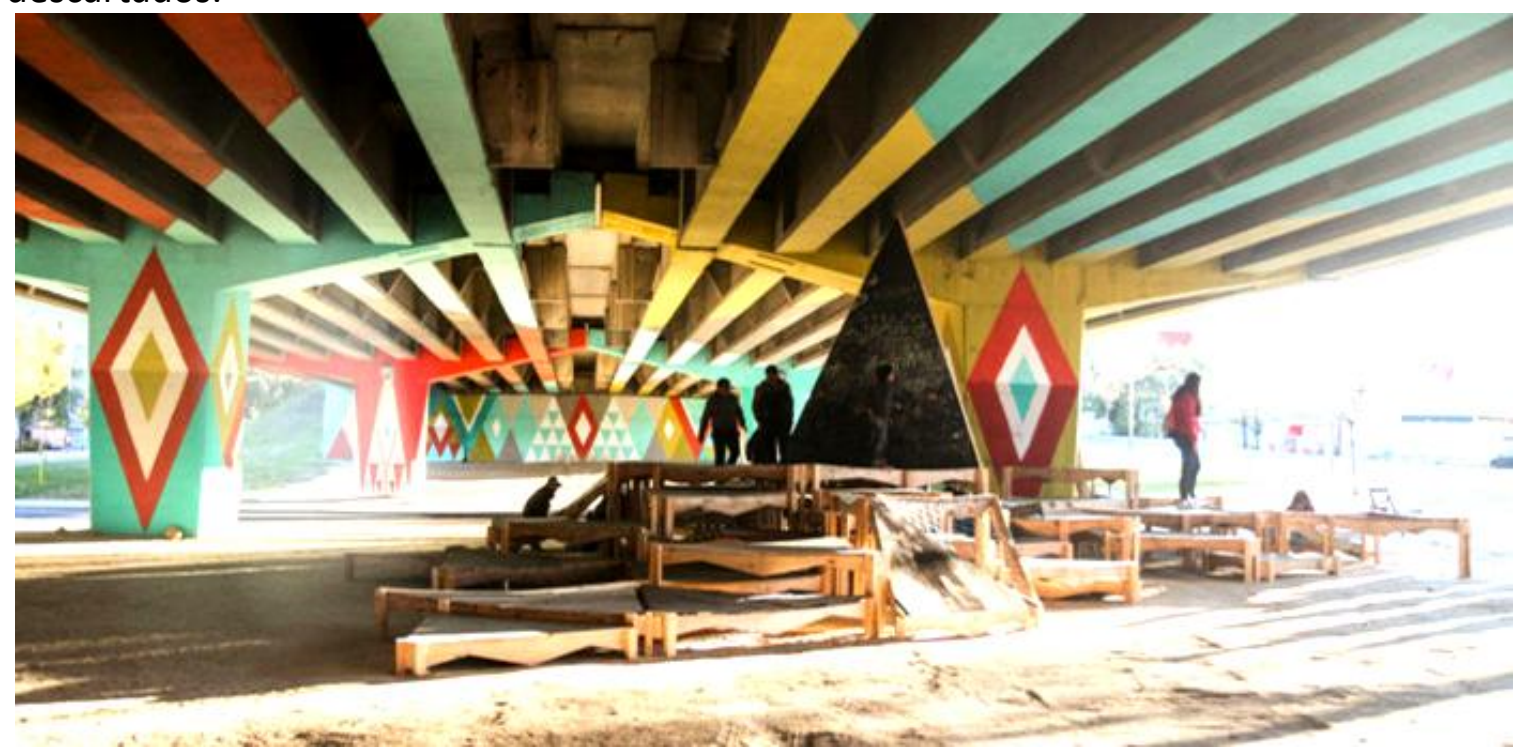

Fonte: <http://www.gizmoweb.org/2014/03/autobarrios-san-cristobal/>. Acesso em: 04 de ago. de 2017.

Ainda com a participação de arquitetos do ponto vista projetual em 2014, o Gruppo 124 liderado pelo arquiteto Renzo Piano - buscou intervir na periferia de cidades italianas. Em Roma, o Gruppo 124 realizou a intervenção Sotto il Viadotto ${ }^{9}$. Na intervenção foram promovidos encontros, oficinas e discussões a fim de definir usos para outros trechos do viaduto da rodovia A90. A cidade eslovaca de Košice, em 2015, de modo semelhante teve o baixio de uma ponte transformado em área pública devido ao projeto Post-Mostom (Figura 6). O projeto dos escritórios Atrium Studio e Esterni previu para a área: café, cinema, palco para conserto, muro de escalada e pista de skate ${ }^{10}$. Embora a intervenção fosse temporária, usuários reivindicaram sua permanência para que ela incentivasse um novo espaço cultural na cidade. Um espaço cultural, que eles poderiam participar ativamente da gestão e da escolha da programação.

\footnotetext{
${ }^{9}$ O reuso temporário do viaduto foi proposto como ferramenta para que fossem testadas outras formas de uso do baixio. Disponível em: <https://sottoilviadotto.wordpress.com/>. Acesso em: 04 de ago. de 2017.

${ }^{10}$ O café e o cinema foram locados em um anfiteatro de madeira. O anfiteatro foi construído por voluntários que participaram das oficinas organizadas pelos escritórios. Disponível em: <http://www.archdaily.com.br/br/01147727/post-mostom-habilitacao-de-um-espaco-publico-sob-uma-ponte-na-eslovaquia>. Acesso em: 04 de ago. de 2017.

Colloquium Socialis, Presidente Prudente, v. 01, n. Especial 2, Jul/Dez, 2017, p.758-765. DOI: 10.5747/cs.2017.v01.nesp2.s0225
} 
Figura 6: Em apenas dez dias os voluntários construíram as instalações do projeto Post-Mostom de 2015.
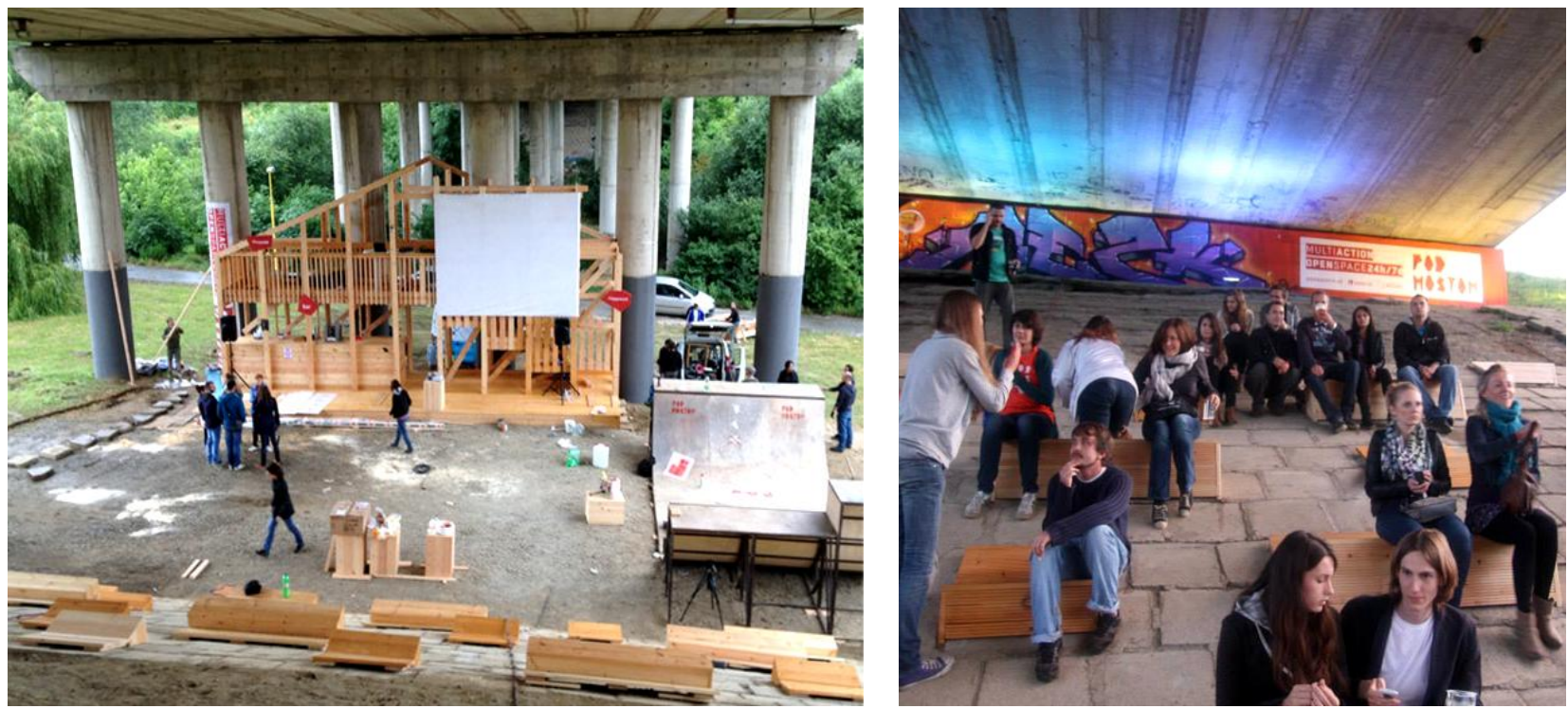

Fonte: <http://www.archdaily.com.br/br/01-147727/post-mostom-habilitacao-de-um-espaco-publico-sob-umaponte-na-eslovaquia>. Acesso em: 04 de ago. de 2017.

Através dessas iniciativas apresentadas busca-se demonstrar como pertinente a ressignificação das estruturas urbanas de maneira contínua, através de formas alternadas de uso: ora para o lazer, ora para ócio ou ora para a transgressão. A ação de construir a coletividade na gestão do espaço público vem sendo definida como importante ${ }^{11}$. Sob essa perspectiva todos os envolvidos com a intervenção têm a liberdade de pensar o que querem para o espaço. Dessa forma, não se assume apenas a visão de um ou de outro. O mérito dessas intervenções pautadas na aceitação das estruturas viárias também está na transformação do que antes era uma barreira intraurbana em um grande limiar que passa a reunir pessoas e diferentes formas de ocupação.

No entanto, ressalva-se que a maioria dos projetos relatados não lida com a questão da ocupação dos baixios de viadutos como áreas de moradia da população em situação de rua, prática presente no Brasil. Nesse sentido, a simples "importação" dessas ações seria um fracasso, uma vez que aqui a realidade é outra.

\section{CONCLUSÃO}

Este trabalho permeou a questão: Por que não experimentar converter os espaços residuais em locais ativos na cidade? Assim teve-se a intenção de destacar o potencial do espaço distante do alcance urbanístico, como os baixios de viadutos, e as formas contemporâneas de ocupação dos espaços públicos. Tendo em vista, que hoje a importância projetual não está apenas no resultado final, mas também no processo, pois se requer do arquiteto e urbanista a formulação de propostas capazes de estimular o preexistente.

Um elemento comum nas intervenções apresentadas é o seu desenvolvimento se dar em etapas. Nas etapas, normalmente se avaliam os ganhos de forma que se alcance o reuso do espaço de maneira contínua. A consciência de reuso do espaço se torna mais significativa por essas intervenções quando o que é proposto utiliza-se de materiais descartados para novos aproveitamentos, como na construção de mobiliários.

\footnotetext{
${ }^{11}$ PELBART, P. P. Parque Augusta. Ou um desejo de rua. Minha Cidade, São Paulo, ano 15, n. 176.03, Vitruvius, mar. 2015. Disponível em: <http://www.vitruvius.com.br/revistas/read/minhacidade/14.176/5455>. Acesso em: 04 de ago. 2017.

Colloquium Socialis, Presidente Prudente, v. 01, n. Especial 2, Jul/Dez, 2017, p.758-765. DOI: 10.5747/cs.2017.v01.nesp2.s0225
} 
Em oposição às amplas intervenções urbanas, moradores vêm rompendo a ideia de isolamento e se unindo para atuar na cidade por meio de intervenções informais. Aparentemente simples, essas intervenções estão mobilizando a coconstrução de espaços públicos.

A partir desse princípio de coletividade os espaços públicos passaram a reunir diferentes pessoas (idade, renda, gênero, etnia). E, aí que está à chance para retomar a função do espaço público, como local para a abertura do diálogo, de entendimento com o outro, de convívio. A identificação dessas ações, pequenas brechas, nos direciona para novas abordagens do espaço urbano. Abordagens que revelam a oportunidade em prol da construção de cidades mais democráticas e conscientes de seus problemas.

\section{REFERÊNCIAS BIBLIOGRÁFICAS}

AGUIAR, V. M. Tamanduatehy Fora do Eixo: próteses arquitetônicas no baixio do viaduto Presidente Castelo Branco. 144 f. Trabalho de Conclusão de Curso (Graduação em Arquitetura e Urbanismo), Faculdade de Ciências e Tecnologia, Universidade Estadual Paulista "Júlio de Mesquita Filho", Presidente Prudente, 2013.

GUATELLI, I. Condensadores urbanos: baixio viaduto do Café academia Cora_Garrido. São Paulo: MackPesquisa, 2008.

Arquitetura dos entre-lugares: sobre a importância do trabalho conceitual. São Paulo: Senac, 2012.

JACQUES, P. B. Errâncias urbanas: a arte de andar pela cidade. ArqTexto, Porto Alegre, n. 7, p. 1625, 2005.

MOEHLECKE, V. Corpos da cidade: territórios e experimentações. ArqTexto, Porto Alegre, n. 7, p. 60-73, 2005.

MOVIMENTO BAIXOCENTRO. BaixoCentro: o grito dos outros. V!RUS, São Carlos, $\mathrm{n}^{\circ}$ 9, semestre 1, p. 1-16, 2013.

ROCHA, E. Os lugares do abandono. Arquitextos, São Paulo, ano 9, n. 097.06, Vitruvius, jun. 2008. Disponível em: <http://www.vitruvius.com.br/revistas/read/arquitextos/09.097/137>. Acesso em: 07 de ago. 2017.

SOUZA, S.; ABASCAL, E. H. S. Estações de metrô em São Paulo: mediações e diálogos na ressignificação do lugar. Arquitextos, São Paulo, ano 15, n. 171.00, Vitruvius, ago. 2014. Disponível em: <http://www.vitruvius.com.br/revistas/read/arquitextos/15.171/5287>. Acesso em: 07 de ago. 2017.

TEIXEIRA, C. M.; CAJADO, L. M.; AGOSTINI, F. Projeto baixios de viadutos da Via Expressa LesteOeste. In: CAMPOS, A.; TEIXEIRA, C. M.; MARQUEZ, R.; CANÇADO, W. (Org.). Espaços colaterais. Belo Horizonte: Instituto Cidades Criativas, 2008. p. 264-82. 